УДК 378

\title{
ОСОБЕННОСТИ РАЗВИТИЯ ИНФОРМАЦИОННО-ОБРАЗОВАТЕЛЬНОЙ СРЕДЫ
}

\author{
Катханова Юлия Федоровна \\ д.П.Н., профессор
}

Левашова Елена Анатольевна

доцент

Канаева Елена Андреевна

ВГБОУ ВО «Московский педагогический государственный университет»

Аннотация: В статье рассматривается современная образовательная среда, история ее становления, особенности, структура и перспективы развития. В ходе исследования отмечено особое значение использования средств мультимедиа в проектировании образовательного контента, а также выделены некоторые достоинства применения дистанционной формы обучения. Значительное внимание уделяется нерешенным проблемам формирования информационной образовательной среды: недостаток качественного обучающего контента; низкий уровень ИКТ-компетентности у преподавателейпредметников. Отсюда актуальность разработанной серии видеоуроков по программам для работы с анимацией: Adobe Animate $\mathrm{CC}$ и Adobe After Effects. В заключении статьи обобщается практический опыт применения разработанного видеоконтента. На основе полученных результатов, выявлено, что оптимальным вариантом для применения видеоуроков является формат смешанного обучения.

Ключевые слова: информационная образовательная среда, проектирование ИОС, технологии мультимедиа, дистанционное обучение, смешанное обучение, образовательные видеоролики.

\section{FEATURES OF DEVELOPMENT OF INFORMATION AND EDUCATIONAL ENVIRONMENT}

\section{Katkhanova Yulia Fedorovna Levashova Elena Anatolievna Kanaeva Elena Andreevna}

Abstract: the article examines the modern educational environment, the history of its formation, features, structure and development prospects. In the course 
of the study, the special importance of the use of multimedia in the design of educational content was noted, and some of the advantages of using distance learning were highlighted. Considerable attention is paid to the unsolved problems of the formation of an information educational environment: lack of high-quality educational content; low level of ICT competence among subject teachers. Hence the relevance of the developed series of video tutorials on programs for working with animation: Adobe Animate CC and Adobe After Effects. In the conclusion of the article, the practical experience of using the developed video content is summarized. Based on the results obtained, it was revealed that the best option for using video lessons is the blended learning format.

Key words: educational information environment, ITS design, multimedia technologies, distance learning, blended learning, educational videos.

Образование - это та сфера жизни, которая играет немаловажную роль в жизни людей. Каждый человек так или иначе взаимодействует с образовательной средой, которую регулирует система образования. Школы, дополнительное образование, колледжи, училища, ВУЗы - это те организации, которые помогают человеку получить необходимые знания, умения и профессиональные компетенции. Характерной чертой системы образования является то, что она быстро адаптируется под новые условия и образовательные среды. Так, раньше у образовательных учреждений было только одно пространство - физическое, в виде здания или комплекса зданий. Данное пространство выполняло интегративную функцию, объединяя все компоненты образовательной среды:

- пространственно-предметный компонент (территория учебного учреждения и все прилегающие к ней здания);

• социально-психологический (администрация, преподавательский состав, учебно-вспомогательный состав, обучающиеся);

- информационно-образовательный компонент (учебные планы, образовательные программы, рабочие программы, методическая база, методы, принципы, техники обучения, формы обучения, расписание и другие информационные материалы).

Однако человек не может находиться в режиме стагнации, так как развитие и стремление к улучшению уровня жизни всегда были для него характерны. Благодаря этим качествам появились цифровые и компьютерные технологии. Их стремительная эволюция и популяризация открыли новые 
возможности для образовательного пространства. Сегодня учебные учреждения имеют возможность создавать дополнительное пространство для образовательных целей - виртуальное. Таким пространством стала информационная образовательная среда (ИОС). Цель ИОС - это не просто внедрение ИКТ-технологий в процесс обучения и использование социальных сетей для различной информации. Это создание комплексной, качественно новой среды, которая специально проектируется для конкретного субъекта или группы людей. Такая среда должна быть четко продуманной структурой с наполнением в виде мультимедийного образовательного контента.

Следует отметить, что каждое учебное учреждение создает свою информационно-образовательную среду. Сюда входит портал или сайт образовательной организации, на котором собрана вся информация: от истории создания учреждения до расписания занятий. Помимо сайта в ИОС могут входить: электронная библиотека, системы дистанционного обучения, группы в социальных сетях, беседы в мессенджерах, онлайн-курсы, олимпиады, профориентационные игры и тому подобное. Все эти части должны быть соединены между собой гиперссылками, по которым можно переходить из одной части ИОС в другую.

Значимость информационной образовательной среды заключается в том, что она предоставляет новые возможности для образовательной деятельности. Любая ИОС несет в себе большой педагогический потенциал, включающий:

- организацию коллективной деятельности и работу в группах;

- индивидуализацию учебного процесса;

- создание ситуации успешности для обучающихся;

- возможность обеспечения деятельностного подхода;

• гибкость организационной структуры с использованием дистанционного обучения;

• возможность интенсификации процесса обучения;

- ориентацию на самообразование;

- социализацию учащихся;

- обеспечение психолого-педагогического сопровождения учебного процесса;

- разный уровень содержания образовательных ресурсов.

Отсюда проектирование такого пространства сейчас стало популярным не только в нашей стране, но и в системах международного образования в виде стажировок в иностранных ВУЗах, которое становится доступным все большему числу людей благодаря: 
- преодолению языкового барьера с помощью современных информационных технологий. Обучающиеся, даже не владея иностранным языком в совершенстве, могут коммуницировать друг с другом благодаря программам и приложениям, которые не только переводят текст, но и распознают голосовой ввод, озвучивая текст на любом языке;

- наличию программного обеспечения для дистанционного или смешанного обучения (Zoom, Microsoft Teams, BigBlueButton, Skype и др.), которые являются частью ИОС, позволяющие иностранным студентам получать образование, находясь в другой стране;

- доступности информации, относящейся к учебному процессу (расписание, важные объявления, новости, события и др.). Обучающиеся могут узнать на сайте образовательной организации.

Важным достоинством информационной образовательной среды является функциональность и удобство использования мультимедийного, интерактивного контента [1, с. 130]. Во-первых, обучающийся может просматривать и изучать материалы из любого города и любой страны, вне зависимости от его местонахождения. Он не привязан к одной точке физического здания образовательной организации [2, с. 23]. Во-вторых, обучающийся имеет неограниченный доступ к материалам и может их использовать столько раз, сколько необходимо. Благодаря такой специфике контента в значительной мере освобождается время преподавателей, позволяя им сконцентрировать внимание на многих других задачах. В-третьих, образовательный процесс становится более индивидуальным.

Однако имеются и нерешенные проблемы ИОС - прежде всего это отсутствие качественного образовательного контента, необходимого для наполнения ИОС. Причина кроется в разработке образовательных ресурсов, включающих современные технологии визуализации учебного материала. К ним мы относим мультимедиа, анимацию, скрайбинг и другие технологии. Особенно остро эта проблема ощущается в высших учебных заведениях, где изучается много узко специализированных дисциплин. Другая причина - еще не все преподаватели обладают ИКТ-компетентностью и навыками, необходимыми для разработки цифровых образовательных ресурсов (ЦОР), видеороликов, презентаций [3, с. 113]. Особые затруднения вызывает внедрение интерактива в готовые видеоролики. На сегодняшний день применение мультимедиа-технологий в информационной образовательной среде - это трендовое и перспективное направление в сфере образования, особенно в 
дистанционном обучении. Следовательно, вопрос об этапах создания качественного контента средствами мультимедиа с его последующим внедрением в образовательную среду сегодня актуален. В этой связи данный вопрос был изучен в рамках магистерской диссертации на тему: «Интегративные функции мультимедиа технологий в образовательной среде». Обоснование для выбора такой темы явилось то, что образовательная среда всегда являлась необъятной системой, содержащей в себе большое количество различной информации. И эта среда непрерывно работала. Но в век информационных технологии она должна была объединить визуальную информацию в единое целое. Оптимальным решением стало применение средств компьютерных технологий, представленных в различных формах: текста, изображения, видео, звука, анимации (рис. 1).

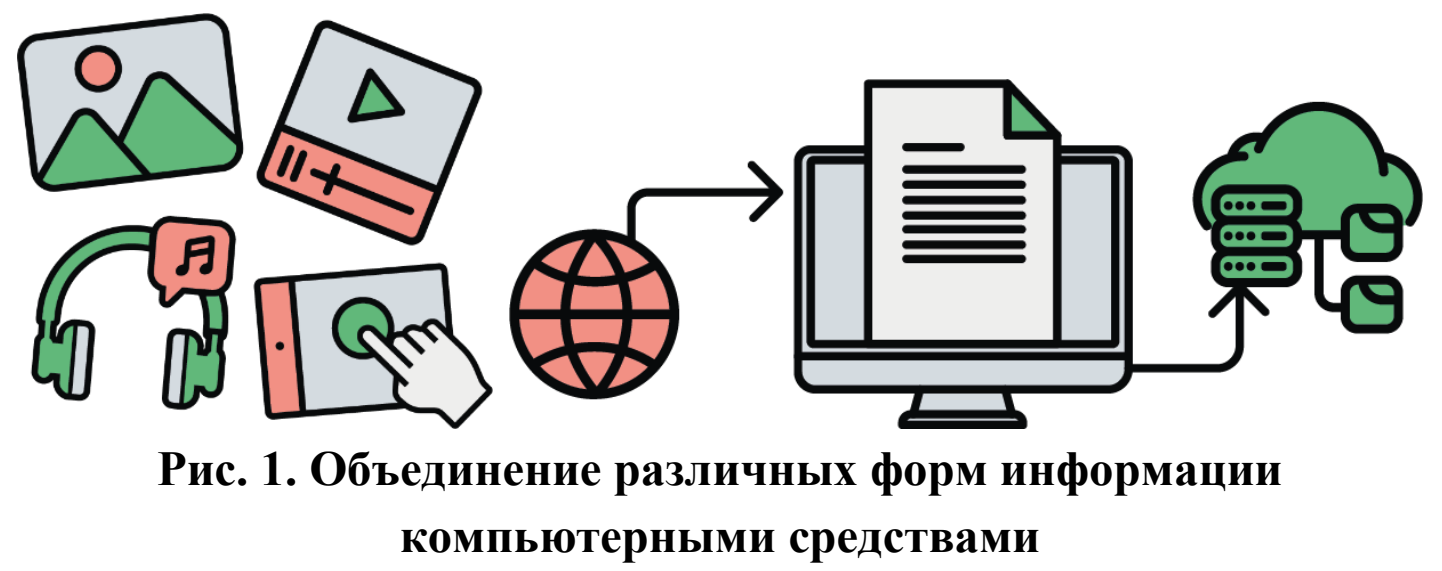

Говоря о создании мультимедийного контента с целью его применения в образовательной деятельности следует отметить три его основные принципа для использования в информационной образовательной среде:

1. Информация должна находиться в хорошо организованной образовательной или информационной среде для того, чтобы человек мог ее легко найти, считать, понять и усвоить.

2. Мультимедийный контент должен обладать несколькими сюжетными линиями, включая ту линию, которую пользователь имеет возможность выстроить сам. Другими словами, это может быть линия «свободного поиска» в рамках предложенной информации.

3. Разрабатываемый мультимедийный продукт должен соответствовать всем правилам педагогического дизайна: проектирование пользовательского интерфейса, юзабилити, продуманная структура с соответствующей системой навигации. 
В ходе нашего исследования была разработана модель мультимедийного образовательного контента в виде двух серий видеороликов, которые могут быть полезны в освоении дисциплин, связанных с анимацией, как для студентов-бакалавров, так и для студентов-магистрантов [4, с. 59]. Необходимость такого проекта заключается в том, что на художественнографическом факультете МПГУ ранее не было создано материалов для дистанционного обучения по дисциплинам «Компьютерные технологии в дизайне (анимация)» и «Моушн-дизайн». Разрабатываемый проект направлен на изучение таких программ для работы с анимацией как Adobe Animate CC и Adobe After Effects. Предполагалось, что использование образовательных видеороликов в процессе обучения может повысить эффективность и скорость изучения программного обеспечения от компании Adobe: Animate $\mathrm{CC}$ и After Effects.

Изучение процесса организации дистанционной формы обучения показало, что в настоящее время уже есть разработанная нормативно-правовая база по дисциплинам «Компьютерные технологии в дизайне (анимация)» и «Моушн-дизайн». Корме того, накоплен определенный практический опыт работы в данной сфере. Однако данные программы ранее преподавались только в формате очного обучения и требовали личного присутствия студента на занятиях. В реалиях нашего времени, преподавание основ пользования программным обеспечением наиболее эффективно при наличии специально разработанной серии видеоуроков, в которых поэтапно показывают и рассказывают о работе в той или иной программе (рис. 2).

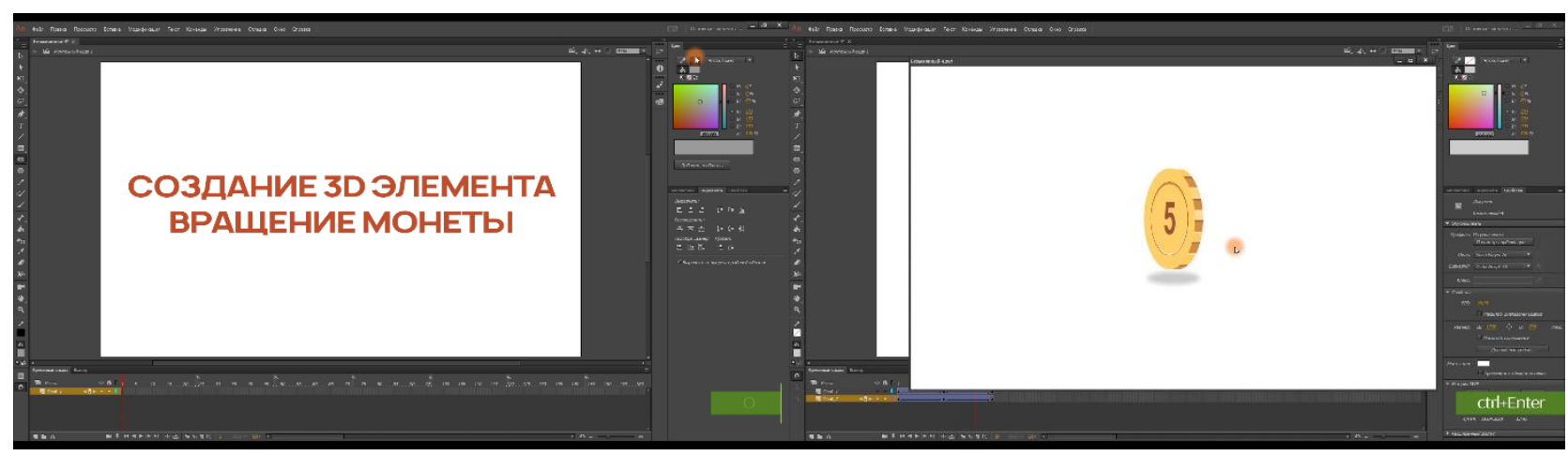

Рис. 2. Скриншоты разработанного видеоурока по созданию 3D элемента

В ходе апробации разработанного мультимедийного контента по теме магистерской диссертации, был проведен анонимный опрос студентов, который показал, что наличие образовательных видеороликов добавляет следующие 
преимущества:

- материал структурирован и логичен (так как к любому видеоматериалу сначала пишется сценарий, продумывается ход занятия, его текст);

- существует возможность просматривать материалы неограниченное количество раз, к тому же есть легкий доступ к перемещению в разные моменты видеоурока с помощью полосы прокрутки, чтобы повторить, уточнить какую-либо информацию;

- повышена эффективность запоминания и усвоения полученной информации, увеличивается вовлеченность студента в образовательный процесс за счет использования различных медиа: видео (захват экрана), текст (субтитры), аудио (озвучка);

Помимо этих преимуществ, есть еще одна немаловажная функция для иностранных студентов — легко перевести один видеоурок на разные языки мира (китайский, японский, английский, немецкий, испанский и другие). Однако помимо явных преимуществ были выявлены и некоторые недостатки такого формата обучения. Некоторые студенты отметили следующие неудобства:

- невозможно заранее предусмотреть абсолютно все, поэтому у обучающихся могут возникать вопросы, на которые не будет ответа в видеоматериале;

- наличие технических проблем (сбои в работе Интернета, электричества, техники). Для нейтрализации этих недостатков необходимо, чтобы у студентов была возможность связаться с преподавателем очно или с помощью мессенджеров, чтобы уточнить у него те моменты, которые остались непонятными после просмотра видеоматериалов. На основе полученных данных, было предложено использовать видеоролики в работе с будущими магистрами в виде смешанного обучения, которое благодаря интегративным функциям мультимедиа технологий, дает возможность часть материала изучать в дистанционном формате. Но при этом не препятствовать очному формату обучения, a, наоборот, только повышать его эффективность, экономя время, отведенное на изучение программ.

\section{Список литературы}

1. Катханова Ю.Ф. Творческие способности и их развитие в графической деятельности // монография - Чебоксары: ИД «Среда», 2018. - 140 с.

2. Кучай Александр Владимирович Интеграция мультимедийных технологий в процесс обучения // Балтийский гуманитарный журнал. 2014. 
№4. - URL: https://www.elibrary.ru/item.asp?id=22803245 (дата обращения: 11.03.2021).

3. Сидорова Л. В., Афанасьева Н. А. Мультимедийные технологии в образовании и обучение студентов педагогических направлений // Научнометодический электронный журнал «Концепт». - 2017. - № 1 (январь). - С. 110-115. - URL: http://e-koncept.ru/2017/170015.htm. (дата обращения: 11.03.2021).

4. Левашова Е.А. Формирование у студентов профессиональных компетенций средствами компьютерной анимации // Воспитание и обучение: теория, методика и практика: материалы III Междунар. науч.-практ. конф. (Чебоксары, 8 мая 2015 г.) / редкол.: О.Н. Широков [и др.] - Чебоксары: ЦНС «Интерактив плюс», 2015. - С. 58-60. URL: https://interactive-plus.ru/ru/article/ 8632/discussion_platform (дата обращения: 11.03.2021).

(ㄱ Ю.Ф. Катханова, Е.А. Левашова, Е.А. Канаева, 2021 